\title{
ENSINO HÍBRIDO APLICADO: RELATO DE EXPERIÊNCIA COM ESTUDANTES DE PÓS-GRADUAÇÃO
}

Applied Blended Teaching: Experience Report with Postgraduate Students

Educación Híbrida Aplicada: Informe de Experiencia con Estudiantes de Posgrado

\author{
Fransciély Valladas Velasques* \\ Sinara Cristiane Tres Soares** \\ Bruno Luce ${ }^{* * *}$ \\ Silvia Castro Bertagnolli**** \\ Lizandra Brasil Estabel ${ }^{* * * * *}$
}

\begin{abstract}
Resumo: O presente relato de experiência tem como foco a aplicação da metodologia de ensino híbrido - modelo de rotação por estações, com estudantes de um curso de pós-graduação stricto sensu. O estudo teve como ponto motivador o baixo índice de pesquisas com ensino híbrido envolvendo estudantes de pós-graduação, o que incentivou os pesquisadores a implementarem o método com sujeitos nesse nível de ensino. Sobre os processos metodológicos, a aplicação de questionários se fez pertinente a fim de coletar dados para posterior análise e para validar os resultados levantados. Trata-se de uma pesquisa aplicada, de natureza qualitativa em que se utilizou da pesquisa-ação, tendo como ponto de partida as observações dos pesquisadores e o áudio coletado durante as atividades propostas. Verificou-se que o ensino híbrido se trata de uma metodologia dinâmica que permitiu a participação ativa dos alunos-sujeitos no processo de aprendizagem.
\end{abstract}

Palavras-chave: Ensino Híbrido. Rotação por estações. Pós-Graduação.

Abstract: This experience report focuses on the application of the blended teaching methodology in the station rotation model. The motivation for the study was the scarce

\footnotetext{
* Mestranda do Programa de Pós-graduação em Informática na Educação do Instituto Federal de Educação, Ciência e Tecnologia do Rio Grande do Sul (PPGIE - IFRS). Orcid: https://orcid.org/0000-0002-9747-6931. E-mail: franscielyv@gmail.com

** Mestranda do Programa de Pós-graduação em Informática na Educação do Instituto Federal de Educação, Ciência e Tecnologia do Rio Grande do Sul (PPGIE - IFRS). Orcid: https://orcid.org/0000-0002-3160-1066. Email: sinara.tressoares@gmail.com

*** Mestrando do Programa de Pós-graduação em Informática na Educação do Instituto Federal de Educação, Ciência e Tecnologia do Rio Grande do Sul (PPGIE - IFRS). Orcid: https://orcid.org/0000-0001-7796-3209. Email: E-mail: brunofluce@gmail.com

**** Doutora em Computação pela Universidade Federal do Rio Grande do Sul (2004). Professora Orientadora Mestrado Profissional em Informática na Educação. Instituto Federal de Educação, Ciência e Tecnologia do Rio Grande do Sul - Campus Porto Alegre - RS / Brasil. E-mail: silvia.bertagnolli@poa.ifrs.edu.br. Orcid: https://orcid.org/0000-0001-7495-6636.

***** Doutora em Informática na Educação pela Universidade Federal do Rio Grande do Sul (UFRGS) e Professora no Instituto Federal de Educação, Ciência e Tecnologia do Rio Grande do Sul (IFRS). Orcid: https://orcid.org/0000-0001-9339-2864. E-mail: lizandra.estabel@poa.ifrs.edu.br
} 
production in Portuguese language on blended education involving postgraduate students, which have encouraged the researchers to implement the method with subjects of this level of instruction. Regarding on the methodological processes, the application of questionnaires was relevant in order to validate the results obtained. This is an applied research, of a qualitative nature, which considered as analysis the observations of the researchers and the audio collected during the proposed activities. Therefore, blended teaching is a dynamic methodology that allowed the active participation of student-subjects in the learning process.

Keywords: Hybrid Teaching. Rotation by stations. Postgraduate.

Resumen: El informe de experiencia se centra en la aplicación de la metodología de enseñanza híbrida, en el modelo de rotación por estaciones. El estudio tuvo como punto motivador la baja producción literaria en lengua portuguesa sobre educación híbrida con estudiantes de posgrado, lo que alentó a los investigadores a implementar el método con el tema de este nivel de educación. Sobre los procesos metodológicos, la aplicación de cuestionarios fue pertinente, para validar los resultados obtenidos. Es una investigación aplicada de naturaleza cualitativa, que utilizó como análisis las observaciones de los investigadores y el audio recogido durante las actividades propuestas. Se descubrió que la enseñanza híbrida es una metodología dinámica que permite la participación activa de los alumnos en el proceso de aprendizaje.

Palabras clave: Enseñanza híbrida. Rotación por estaciones. Posgraduación.

\section{Introdução}

As tecnologias têm influenciado como as pessoas se relacionam umas com as outras, como se entretêm e como consomem bens e serviços de uma forma geral. Embora toda a evolução tecnológica tenha sido incorporada em várias instâncias da sociedade, ainda existem campos que não se modificaram de modo tão significativo com o passar dos anos, como, por exemplo, o sistema educacional. $\mathrm{O}$ ambiente escolar continua utilizando a estrutura física baseada em quadro, cadeiras enfileiradas e com um professor que transmite o saber a frente da turma, ou como argumentam Horn e Staker (2015), continuamos adotando o modelo industrial de educação, que é apontado como insuficiente, pois os estudantes possuem necessidades de aprendizagem diferentes, em momentos diferentes.

Nesse contexto, surgem as metodologias ativas de aprendizagem que defendem um modelo de ensino em que os alunos são os protagonistas do seu processo de aprendizagem. Dentre as metodologias ativas, uma das que vem se destacando é o ensino híbrido, que pode ser considerado uma alternativa ao modelo de ensino tradicional (BACICH; MORAN, 2018). O ensino híbrido $(\mathrm{EH})$ mescla a educação presencial com a virtual e pode ser desenvolvido através de quatro modelos: Rotacional, Flex, à la Carte e Virtual Aprimorado. Ainda, inseridas no modelo Rotacional existem quatro subdivisões: Rotação por Estações, Rotação Individual, Laboratório Rotacional e Sala de Aula Invertida (HORN; STAKER, 2015). Assim, considerando essa metodologia de ensino, o artigo tem como questão central de investigação: qual a viabilidade da aplicação do modelo de ensino híbrido para alunos de pós-graduação stricto sensu?

Nesse sentido, buscando encontrar publicações sobre a temática a fim de identificar a pertinência de realizar a investigação pretendida, bem como apoiar o estudo em pesquisas já realizadas, foram feitas buscas nas seguintes bases: Periódicos Capes, Scielo, Google Acadêmico (Google Scholar). Para a busca, foram utilizados arranjos com os seguintes termos: 
ensino híbrido, laboratório rotacional e pós-graduação, delimitando as publicações em língua portuguesa realizadas nos últimos cinco anos (2013 a 2018). A partir desta busca não foi possível recuperar nenhum estudo, o que demonstra a relevância da realização de pesquisas sobre o tema proposto.

A metodologia de aplicação do trabalho seguiu alguns aspectos norteadores da aprendizagem significativa (AUSUBEL, 2003). Assim, o ponto de partida foi a aplicação de um questionário para identificar os conhecimentos prévios dos estudantes sobre o tema que estava sendo abordado (que era o $\mathrm{EH}$ ), pois um dos aspectos que mais influencia a aprendizagem é aquilo que o aprendiz já sabe (MOREIRA, 2012).

As questões formuladas para o pré-teste visavam a identificar os conhecimentos que os alunos já possuíam sobre $\mathrm{EH}$, especialmente quanto: ao que caracteriza esse modelo de ensino, as qualidades desta proposta metodológica, os benefícios que proporciona, as estratégias de $\mathrm{EH}$ existentes e as possibilidades de aplicação e qualificação no contexto de ensino tradicional. Após realizar o pré-teste, que permitiu identificar as lacunas de aprendizagem, foi realizada uma aula expositiva dialogada, a qual incluiu a rotação por estações de trabalho e uma discussão final, na qual foram gravados os diálogos sobre o tema em debate, e, posteriormente, foi realizado um segundo questionário. Tal questionário possuía questões com conteúdo correspondentes às perguntas formuladas no pré-teste, que permitiu identificar se ocorreu, ou não, evolução da aprendizagem.

Assim, o artigo prossegue organizado em seções: a seção 2 aborda uma apresentação de aspectos teóricos do ensino híbrido; a seção 3 relata a experiência realizada, bem como a abordagem metodológica utilizada para o desenvolvimento do trabalho; a seção 4 destaca os resultados alcançados após aplicação do estudo e, na seção 5, as considerações finais sobre o trabalho realizado.

\section{Ensino híbrido}

O ensino híbrido para Bacich, et al. (2015) representa a mistura, a combinação, a mescla (blended), tanto de espaços, como de tempos, de atividades, de metodologias e de públicos. Os autores relacionam aos métodos utilizados no EH à culinária, em que se pode cozinhar receitas diferentes usando os mesmos ingredientes e obter novos sabores.

Assim, a mistura proposta pelo EH combina tanto atividades presenciais como as realizadas através do uso de Tecnologias Digitais da Informação e Comunicação (TDIC) nas abordagens pedagógicas (MORAN; BACICH, 2018). Com a evolução tecnológica que foi alcançada, é possível ensinar e aprender de muitas maneiras, em diferentes espaços físicos e temporais; e, ainda, em ambientes virtuais ou físicos. Desse modo, a diversidade de situações e ambientes em que o aluno pode aprender ativamente é ampliada, uma vez que não se restringe ao ambiente da sala de aula e/ou à necessidade e à dependência do professor para o desenvolvimento de tarefas de aprendizagem. Esta abordagem pedagógica tem o foco no processo de aprendizagem centrado no aluno, que ultrapassa a metodologia tradicional, focada apenas na transmissão de informação pelo professor (BACICH, et al., 2015).

Os autores sugerem, a partir de Coll et. al. (2010), que há um triângulo interativo, do qual fazem parte o professor, os estudantes e os conteúdos. Todos estes são modificados pela inserção das tecnologias digitais no dia a dia dos indivíduos, oferecendo novas formas de interação e criando novas relações entre os três partícipes do triângulo. Os mesmos autores propõem, assim, que os três vértices do triângulo são compostos pela relação, conforme demonstra o Quadro 1: 
Quadro 1 - Três Vértices do Triângulo segundo Coll et. al. (2010)

\begin{tabular}{|c|c|c|}
\hline Professor-Tecnologia & Aluno(s)-Tecnologia & Professor-Aluno(s)-Tecnologia \\
\hline $\begin{array}{c}\text { O educador tendo o papel de buscar } \\
\text { a ferramenta tecnológica mais } \\
\text { adequada para os objetivos } \\
\text { educativos propostos, visando a } \\
\text { construção do conhecimento pelo } \\
\text { aluno }\end{array}$ & $\begin{array}{c}\text { A interação do aluno com a } \\
\text { ou em grupos de estudantes } \\
\text { ounia, seja individualmente }\end{array}$ & $\begin{array}{c}\text { Professor como mediador do uso da } \\
\text { ferramenta tecnológica pelo aluno. }\end{array}$ \\
\hline
\end{tabular}

Fonte: Elaborado pelos autores (2019).

Ainda, segundo os autores Coll et al. (2010), o modo de pensar e de construir conhecimentos foi modificado na medida em que as tecnologias digitais têm proporcionado o acesso rápido a uma quantidade enorme de informações. Dessa forma, o educador precisa estar atento ao tipo de impacto que a tecnologia sugerida pode ter nos modos de pensar e agir de seus alunos. Assim, pode aproveitar o potencial de construção coletiva e compartilhamento que as tecnologias proporcionam.

Nesse contexto, o professor também necessita adaptar sua proposta de ensino e reconfigurar as aulas, de maneira a favorecer os momentos de interação, colaboração e envolvimento, através do uso das tecnologias digitais. Assim, o EH vem contribuir com o docente justamente oportunizando a combinação metodológica que engloba tanto o ensino quanto a aprendizagem.

Segundo Christensen et al. (2013), existem os modelos de EH que são considerados sustentados e outros, disruptivos. Relacionando com outras áreas, os autores apontam que modelos sustentados são aqueles em que se combina a antiga tecnologia com a nova para criar algo que possui melhor desempenho. No campo da educação, um modelo de EH sustentado é aquele em que se utiliza tanto recursos tradicionais de ensino como as novas tecnologias. Assim, consideram-se que são modelos sustentados: rotação por estações, laboratório rotacional e sala de aula invertida. Já os modelos de rotação individual, flex, à la carte e virtual enriquecido, são considerados disruptivos, pois "rompem" com o modelo tradicional de ensino, se distanciando e preservando pouca ou nenhuma semelhança. Em função desta característica de rompimento com os modelos já existentes, os modelos disruptivos necessitam de gestão e organização educacional diferenciada, uma vez que exigem infraestrutura física e tecnológica própria (computadores, tablets e outros recursos) e profissionais, sendo necessários para além do professor da disciplina ou da estrutura tradicional da sala de aula, e, por isso, a dificuldade de sua implementação no contexto escolar.

Para aplicação da metodologia de EH do presente estudo foi utilizado o modelo de rotação por estações que, como o próprio nome sugere, está organizado de modo que os alunos sigam "um roteiro pré-estabelecido pelo professor, passando algum tempo imersos em diferentes estações de ensino em que, pelo menos uma, tem que ser online." (BLENDED LEARNING UNIVERSE, 2018). Cada estação pode envolver determinada tarefa, como vídeos, discussões em grupos, atividades de escrita, leitura, incluindo ao menos uma atividade online. Os estudantes formam grupos, sendo que cada grupo realiza uma das tarefas assumindo, naquele momento, uma estação. Ao final do período estipulado, eles trocam de estação, desempenhando outra tarefa correspondente à nova estação, conforme representado pela Figura 1. 
Figura 1 - Sequência didática da aula de EH no modelo de rotação por estações
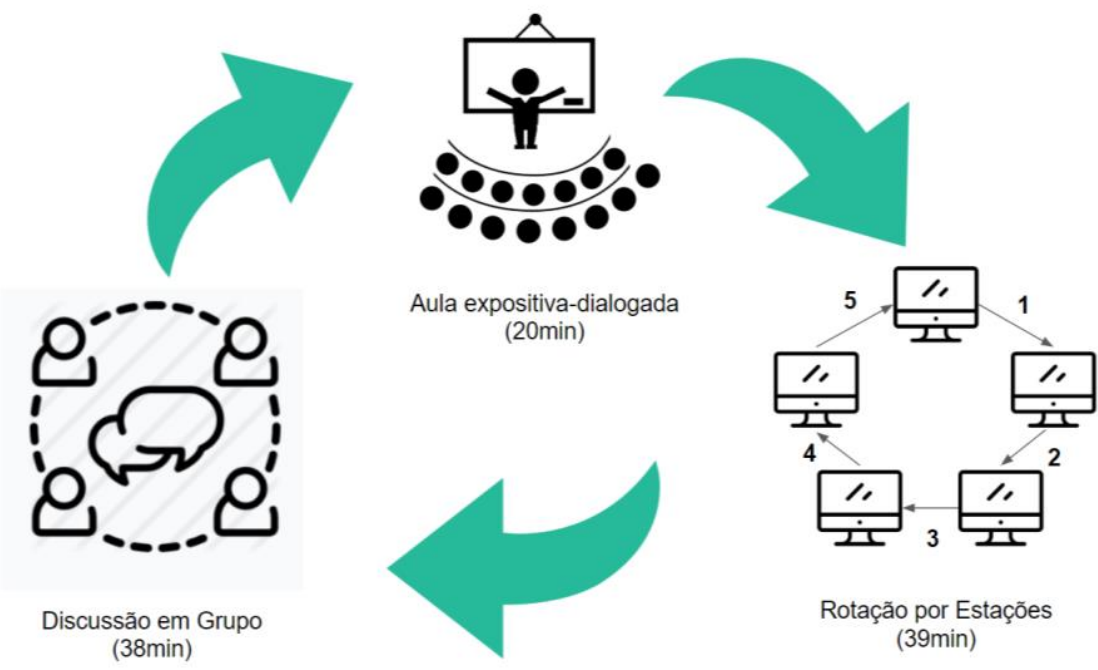

$$
\begin{gathered}
\text { Rotação por Estações } \\
\text { (39min) }
\end{gathered}
$$

Fonte: Elaborado pelos autores (2019).

No caso do modelo de rotação por estações é importante que as tarefas sejam independentes, mas integradas ao contexto de aprendizagem proposto, para que todos os alunos, ao final, tenham acesso ao mesmo conteúdo. O professor tem o papel de mediador, sendo que ao início, busca levantar os conhecimentos prévios e, ao final, estimula a sistematização e síntese dos aprendizados. O ideal é que exista um profissional capacitado para dar apoio em cada uma das estações. No caso deste trabalho isso foi possível, pois a pesquisa foi desenvolvida com o docente da disciplina e outros três pesquisadores envolvidos diretamente com este trabalho.

\subsection{Aprendizagem no ensino híbrido}

O processo de aprendizagem, segundo a epistemologia construtivista, envolve a interação e relação do sujeito com o objeto do conhecimento, ou seja, o conhecimento ocorre através das interações que realiza com o meio (ABREU et. al, 2010). Assim, ao planejar atividades que envolvem $\mathrm{EH}$, o professor precisa considerar o aspecto relacional para a construção do conhecimento.

Desse modo, um importante passo a ser dado pelo docente é justamente identificar quais conhecimentos os sujeitos possuem sobre o assunto a ser trabalhado, uma vez que isto contribui para a identificação das possibilidades de assimilação e acomodação para posterior adaptação dos alunos diante do objeto de conhecimento. Assim, considerando que o processo de assimilação ocorre quando a pessoa integra uma nova informação às estruturas cognitivas prévias, o processo inicial que o EH propõe, de levantamento de conhecimentos anteriores, torna-se essencial para que o aluno tenha condições de mediar essa relação entre o conhecido e o novo conhecimento (TAFNER, 1997). Além disso, pode ocorrer do estudante não conseguir assimilar o conhecimento por não encontrar condições para isso em sua estrutura cognitiva, necessitando da acomodação do novo conhecimento em uma nova estrutura cognitiva, por intermédio da criação de um novo esquema, que também necessita da observação do educador para que a acomodação ocorra (PIAGET, 1976). 
Nessa linha, é importante abordar as contribuições de Ausubel (2003) quanto a aprendizagem significativa, que é baseada na interação dos conhecimentos prévios e os novos conhecimentos. Neste contexto, cabe trazer o conceito de ideia âncora ou subsunçor, que se constituem nos conhecimentos específicos existentes na estrutura de conhecimentos do indivíduo e que podem servir de "elo de ligação" para a atribuição de significados aos novos conhecimentos. Assim, ao propor a aprendizagem de novos conteúdos através das inúmeras possibilidades que o EH apresenta, o educador precisa estar atento a esses processos que ocorrem durante a construção do conhecimento, de modo a facilitar para que a aprendizagem dos alunos seja significativa, por intermédio das opções pedagógicas adotadas.

\section{Relato da experiência}

O presente trabalho apresenta uma experiência educacional a partir da abordagem pedagógica de ensino híbrido. O estudo em questão foi aplicado em uma aula na turma de Pósgraduação stricto sensu na área de Informática na Educação no Instituto Federal do Rio Grande do Sul. Assim, este estudo se caracteriza por uma pesquisa-ação, que se trata de um tipo de investigação empírica em que os participantes e pesquisadores estão envolvidos na resolução de um problema. Fonseca (2002, p.34) afirma que este tipo de pesquisa "pressupõe uma participação planejada do pesquisador na situação problemática a ser investigada.". Ou seja, o pesquisador participa do processo de aplicação da metodologia para a resolução da problemática.

Inicialmente, foi aplicado um questionário com 10 questões, que foi disponibilizado no ambiente virtual da turma, sendo que 13 alunos optaram por participar da experiência aqui descrita. $\mathrm{O}$ intuito da aplicação do questionário era de verificar o conhecimento prévio destes estudantes sobre uma determinada unidade de aprendizagem da disciplina. Essa metodologia está embasada na teoria de Ausubel, que afirma que a aprendizagem significativa ocorre quando o novo conhecimento é construído a partir de uma estrutura cognitiva já existente (AUSUBEL, 2003). Ou seja, o professor deve ter claro qual o conhecimento prévio que o aluno possui sobre o tema para que, a partir disso, apresente situações que permitam desenvolver o conteúdo com base neste conhecimento, viabilizando assim a construção de novos conhecimentos.

Neste sentido, a partir da verificação do conhecimento prévio dos alunos, foi elaborada uma aula expositiva-dialogada para explicar os aspectos teóricos da unidade de aprendizagem selecionada, cujo conteúdo da aula era justamente o EH. Após esse momento, foi aberto um espaço para discussão do tema e foi realizada uma análise de sua aplicabilidade em outras situações reais, ou seja, foi realizado um contraponto entre a teoria e a prática. Em seguida, foi realizada uma atividade prática que teve como base o modelo do ensino híbrido de rotações por estações.

Os alunos foram divididos em cinco grupos de 2 a 3 pessoas e, após, ocorreu um sorteio para indicar qual a estação que cada grupo iniciaria. Para o desenvolvimento da atividade é essencial prever a quantidade de estações (HORN; STAKER, 2015). No caso deste trabalho, foram previstas seis estações, mas como alguns alunos se ausentaram na aula em que a prática foi realizada, percebeu-se que os grupos ficariam prejudicados com 1 ou 2 membros, assim o número de estações foi reduzido e isso viabilizou aplicar a estratégia com um número menor de integrantes, mas que configurasse a ideia de grupo, e não de indivíduo. Assim, essa atividade contou com a participação de 10 pessoas.

A partir disso, a atividade foi operacionalizada com 5 estações, posicionadas em computadores distantes uns dos outros, e com edição colaborativa usando a ferramenta do 
Google Docs. Em cada estação, havia um trecho do livro intitulado ensino híbrido de Bacich, et al. (2015), para proporcionar uma reflexão sobre o conteúdo e sua aplicabilidade no contexto educativo. O tempo destinado para a realização da atividade proposta em cada estação era diferente, considerando que, além do trecho de reflexão, deveria ser formulada uma pergunta para o próximo grupo a realizar a atividade naquela estação. Assim, ao ocorrer a rotação para a estação seguinte, os alunos liam a reflexão inicial (inserida pelos docentes daquela aula) e a do grupo anterior, além de responder à pergunta proposta por este mesmo grupo. De modo a identificar a produção realizada, foram usadas cores que identificavam o constructo de cada estação. Neste sentido, o tempo estipulado foi de 6 minutos para a primeira e a segunda rotação, passando para oito, nove e dez minutos respectivamente nas estações 3 , 4 e 5 .

Ao término da rotação por todas as estações, a turma se reuniu novamente com o intuito de discutir sobre os pontos positivos e negativos da metodologia e sobre as produções realizadas nas estações. Essa discussão foi mediada por dois dos pesquisadores e gravada por 39 minutos com o consentimento dos participantes e será descrita na próxima seção. Além disso, foi aplicado um segundo questionário com os participantes para verificar, com perguntas correlacionadas às perguntas do pré-teste, se houve ou não alguma evolução da aprendizagem, quanto à conceituação, qualidades, benefícios, estratégias e possibilidades de aplicação do EH, bem como sua relação com o ensino tradicional. Assim, considerando que três alunos não participaram da segunda avaliação por terem se ausentado na aula prática, foi utilizada uma média dos acertos de cada questão para esses alunos, considerando que as avaliações do primeiro teste não foram identificadas.

\section{Percepções do Modelo Pedagógico Adotado}

Conforme já mencionado, ao concluir a rotação pelas estações foi realizada uma discussão com os participantes sobre a estratégia de EH adotada. Esta discussão foi gravada e alguns dos relatos realizados pelos participantes foram transcritos utilizando a linguagem adotada pelos estudantes durante a discussão. Assim, durante esse momento de debate, os participantes fizeram várias argumentações sobre a prática. $\mathrm{O}$ primeiro ponto identificado como crucial para se utilizar essa abordagem diz respeito ao tempo: pode-se inferir que a questão do tempo em relação a quantidade de informações afeta o nível de interação dos alunos com a atividade. Neste sentido, o participante (P7) relata que o tempo para realizar a atividade foi curto e, com isso, não foi possível ler todos os trechos que os demais grupos elaboraram, responder à pergunta e ainda propor para o grupo seguinte uma nova questão. Neste sentido, relata que dificultou o uso da estratégia: "o tempo, acho que foi um pouco curto, não dava para ler todas as perguntas. Nós líamos o principal e já íamos respondendo, e a última pergunta ficava semelhante ao que outro grupo já tinha feito."

$\mathrm{Na}$ mesma perspectiva, o (P1) complementa que devido ao tempo, as perguntas se tornaram repetitivas. Que deveria ter estipulado um tempo para ler o texto que estava nas estações e depois um tempo para formular a nova pergunta. "E depois deixar no 'quadro' para que as equipes soubessem o tempo que tinham para ler e se organizassem para fazer as perguntas.”. Ou seja, o tempo para a realização da atividade deveria estar visível no quadro para que os participantes se organizassem quanto ao tempo de leitura dos trechos, resposta da pergunta, bem como a elaboração da pergunta para o próximo grupo. O participante (P9) também afirma que ao realizar uma atividade com tempo estipulado, implica na compreensão da atividade, "essa coisa de tempo é complicado, pois fica uma pressão. Pois era um assunto que tinha que ler com mais calma, para entender melhor." 
Assim, o participante (P3) sugere que seja retirado o tempo de rotação das estações, "uma solução que eu encontrei agora, é não ter tempo. E o grupo que termina troca com o outro grupo que terminou". A descrição mencionada pelo participante refere-se ao modelo Flex, no qual não há tempo estipulado para a realização da atividade, seguindo o ritmo do estudante de forma mais personalizada (BACICH, et al, 2015). No entanto, como apontam Ribeiro e Medeiros $(2017$, p.4) o importante é que "o tempo total de cada estação deve ser suficiente para que os estudantes realizem as atividades propostas e alcancem o objetivo de cada estação." Neste caso, analisando-se as produções dos alunos, apesar da sugestão indicada, os alunos tiveram êxito nas atividades propostas em cada estação, atingindo o objetivo de ler, responder às perguntas dos colegas e formular uma nova questão para o próximo grupo responder. Apesar disto, é importante reconhecer a possibilidade de que o tempo estipulado tenha sido insuficiente ou que poderia ser maior na primeira estação, evitando que a inexperiência com o método possa interferir no aproveitamento da aprendizagem. Isso fica evidenciado na fala de P11, que afirma que sua maior dificuldade foi na primeira estação até se ambientar, por isso sugere que o tempo seja maior no início: "Tivemos a dificuldade de entender, como era primeira estação estávamos nos ambientando, acho que foi um tempo curto."

Como pontos positivos da prática, o (P1) afirma que conseguiu diferenciar os modelos de EH e compreender as dúvidas preexistentes: "eu consegui fixar, pois eu confundia os conteúdos por serem parecidos. Aí, eu consegui perceber as diferenças entre eles." Além disso, o participante (P9) salienta: "achei muito legal, pois vocês introduziram a partir do trecho, mas conseguimos ver o que os colegas achavam com as perguntas." Assim, observa-se que é possível compreender, a partir da prática de $\mathrm{EH}$, de que maneira as pessoas interpretam o mesmo trecho em diferentes perspectivas e de acordo com a sua visão sobre aquela realidade apresentada pelo autor. O participante (P5) afirma que "tudo funcionou, foi bem bacana, acho que só o tempo poderia ser um pouquinho mais. Mas o resto foi legal."

Por fim, o (P2) sugere que seja utilizado o método de sala de aula invertida junto com o modelo de estações para ter um melhor aproveitamento. Neste modelo citado por P2, "[...] a teoria é estudada em casa, no formato on-line, e o espaço da sala de aula é utilizado para discussões, resolução de atividades, entre outras propostas" (BACICH, et al., 2015, p. 15). Ainda, P2 também aponta:

eu senti um pouco de dificuldade, que a gente não tinha lido nada sobre. Se eu, no mesmo tipo de aprendizagem, tivesse lido alguma coisa, depois chegado aqui e reforçado. Acho que as minhas respostas seriam melhores do que as que eu dei. (P2, 2019).

Neste sentido, pode-se observar que a discussão dos alunos e a comparação de respostas no questionário mostram uma aprendizagem significativa independentemente dos fatores que possam ter dificultado no momento da realização da atividade. Percebe-se, também, uma preocupação dos estudantes com relação ao conhecimento da estratégia pedagógica utilizada. Eles indicaram que gostariam de se apropriar dos modelos em momento prévio para compreender melhor o seu papel no ensino híbrido, no modelo de rotação por estações.

Considerando a aplicação dos questionários antes e depois da aula expositiva-dialogada e da aplicação do modelo de rotação por estações, pode-se comparar os resultados obtidos com o pré-teste e o pós-teste. Os questionários eram compostos com perguntas fechadas que continham apenas uma questão correta e que eram equivalentes em termos de conhecimento testado, ou seja, a pergunta 1 do pré-teste é equivalente à questão 1 do pós-teste, contendo enunciados descritos em um formato diferente, porém abordando o mesmo tema. Salienta-se que os participantes não tiveram contato com os conceitos de $\mathrm{EH}$ em nenhum outro momento 
anterior ao pré-teste dentro do programa de pós-graduação em questão, uma vez que este conteúdo somente é previsto na disciplina em que a pesquisa foi aplicada.

Analisando-se o Gráfico 1, esquematizado abaixo, é possível observar que $77 \%$ dos alunos apresentaram maior incidência de respostas corretas às questões ao responder o pósteste, se comparado ao pré-teste. Além disso, $8 \%$ da turma mantiveram o mesmo número de acertos e $15 \%$ erraram uma questão a mais, em relação ao anterior. Com esse resultado, é possível afirmar que os novos conceitos foram ancorados nos subsunçores relevantes preexistentes na estrutura cognitiva da maioria dos estudantes (MOREIRA, 2012), uma vez que demonstraram uma evolução de conhecimentos desde o pré-teste.

Gráfico 1- Comparação do Aprendizado antes e depois da prática de EH

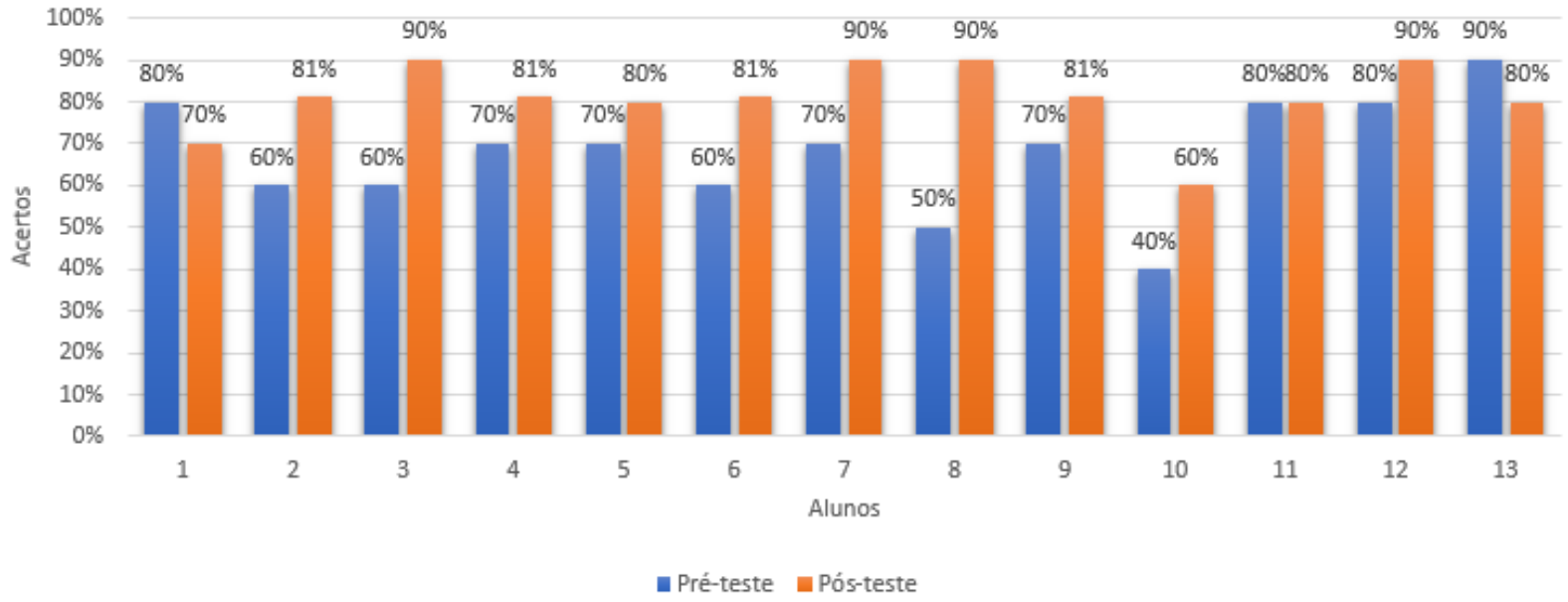

Fonte: Elaborado pelos autores (2019).

Quando comparado o nível de acerto nas questões, observa-se que $80 \%$ melhoraram seu desempenho após a aplicação do modelo de EH, comparado ao pré-teste. Neste sentido, compreende-se que a aplicação do modelo combinado à teoria da aprendizagem significativa de Ausubel (2003), possibilita abordagem e foco em conteúdos que os alunos possuem maior dificuldade.

Destacam-se no Gráfico 2, a elevação no nível de acertos nas questões 2, 8 e 9, as quais abordavam os conhecimentos sobre: o termo também utilizado para denominar o EH (blended learning), os modelos de $\mathrm{EH}$ existentes e as propostas que o $\mathrm{EH}$ oferecem para a qualificação do ensino tradicional. Todos estes conteúdos foram abordados na aula expositiva-dialogada e nas estações estabelecidas para as rotações. 

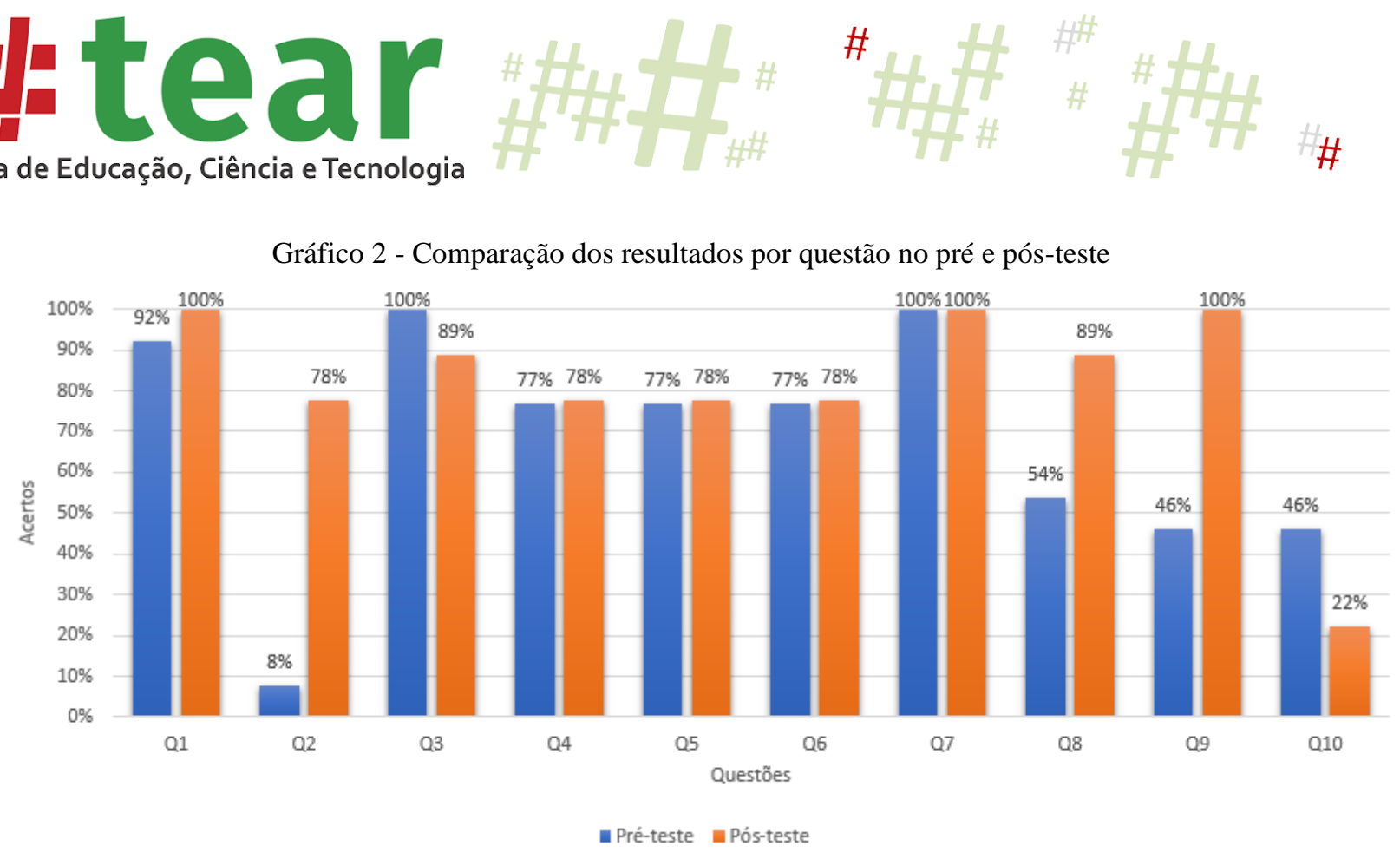

Fonte: Elaborado pelos autores (2019).

Nesse sentido, um importante fator que pode ter contribuído para os resultados de aprendizagem foi justamente a forma como a aula foi organizada, pois ela foi baseada nas informações obtidas pelo diagnóstico do conhecimento prévio que os alunos já possuíam sobre o assunto (questionário pré-teste), partindo do conhecido para o novo conhecimento. Nesse sentido, a escolha dos diferentes trechos do livro que fundamentou a estratégia de rotação por estações foi baseada nas respostas que os alunos apresentaram no questionário prévio sobre o assunto, buscando aprofundar especialmente os conteúdos em que tiveram maior dificuldade de compreensão. Assim, a busca por facilitar o processo de assimilação do novo conhecimento de modo a integrá-lo às estruturas cognitivas prévias pode ter contribuído para os resultados apresentados quanto à aprendizagem de conteúdos antes não conhecidos (TAFNER, 1997).

Cabe apontar, também, em relação aos resultados do Gráfico 2, que houve um decréscimo de acertos quanto à questão 10 , comparando-se pré e pós-teste. A referida questão abordou os benefícios da aplicação do EH e analisando-a, identificou-se que o nível de dificuldade nas opções de resposta pode ter influenciado no desempenho em função da especificidade do benefício questionado no pós-teste, uma vez que o segundo questionário explorava a interação entre professores no EH de um modo diferente do que no pré-teste.

\section{Considerações finais}

Considerando o objetivo de verificar a viabilidade do método para o público, pode-se observar que este modelo de aplicação é viável a alunos de pós-graduação e apresenta resultados satisfatórios de aprendizagem, como identificado na apresentação dos resultados, especialmente na Gráfico 1, o qual demonstra o crescimento da aprendizagem dos participantes quanto ao conteúdo abordado. Porém, cabe ressaltar que o método exige planejamento para uma aula composta por vários períodos para a sua execução, de modo que seja possível realizar a dinâmica e fechamento do estudo em tempo hábil. Além disso, considerando-se os achados e as sugestões dos próprios participantes, indica-se que após aplicar o questionário para verificar o conhecimento prévio, seja disponibilizado aos alunos um material antes da aula prática, podendo seguir um misto juntamente com o modelo de sala de aula invertida como estratégia pedagógica para favorecer a aprendizagem dos estudantes. Assim, a parte inicial da aula pode 
ser uma discussão geral sobre o tema. Após, o professor pode apresentar uma breve aula expositiva-dialogada abordando os conteúdos em que os alunos apresentaram mais dificuldades no questionário prévio, bem como esclarecendo as dúvidas e, por fim, a aplicação do modelo de rotação por estações.

A experiência realizada permitiu identificar questões importantes ao se utilizar esse modelo: o professor deve realizar um planejamento consistente da aula, o que viabiliza que ele possa acompanhar os estudantes em grupos menores e, consequentemente, ao conceder feedbacks imediatos com relação aos estudantes, é possível perceber que eles desenvolvem habilidades não previstas nos currículos tradicionais, pois tiveram que trabalhar com tecnologias e de forma colaborativa. Ainda, o uso de recursos tecnológicos e ferramentas digitais permite a inclusão de novas formas de aprender e ensinar. Além disso, ao mesmo tempo em que se concentravam e aprendiam um novo conteúdo, também planejavam como oferecer aos próximos colegas que chegariam àquela estação de aprendizagem uma pergunta que provocasse novas reflexões.

Apesar disso, pode-se analisar que um dos pressupostos da metodologia ativa, que é o respeito ao ritmo de estudos dos alunos, diverge da metodologia do modelo de rotação por estações, uma vez que, conforme as falas dos participantes, não prezou pelo tempo de cada grupo de participantes para realização da atividade. Assim, é válida a proposta de um estudo sobre os impactos, tanto positivos como negativos, da determinação de um tempo específico para o trabalho em uma estação de aprendizagem, buscando identificar se o fato do método de rotação por estações apresentar esta regra de funcionamento contribui para o desempenho dos estudantes diante do conteúdo apresentado.

Considerando a dificuldade na realização das atividades ao ter um tempo estipulado, sugere-se, como estudo futuro, a elaboração de uma atividade a partir do Modelo Flex, em que o aluno possui maior autonomia para realizar a atividade de acordo com seu ritmo. Assim, é possível verificar, a partir da aplicação do modelo mencionado, se os estudantes teriam maior aproveitamento em relação à aprendizagem sem que a questão do tempo possa influenciar nos resultados.

\section{Referências}

ABREU, L. C. de et al. A epistemologia genética de Piaget e o construtivismo. Revista

Brasileira de Crescimento e Desenvolvimento Humano, São Paulo, v.20, n.2, p.361-366, 2010. Disponível em: https://goo.gl/bKGTx2. Acesso em: 17 nov. 2018.

AUSUBEL, D. P. Aquisição e Retenção de Conhecimentos: Uma perspectiva Cognitiva. Tradução Lígia Teopisto. Lisboa: Plátano, 2003.

BACICH, L. et al. Ensino híbrido: personalização e tecnologia na educação. Porto Alegre: Penso, 2015.

BACICH, L.; MORAN. J. (org.). Metodologias ativas para uma educação inovadora: uma abordagem teórico-prática. Porto Alegre: Penso, 2018.

BLENDED LEARNING UNIVERSE. Modelos de ensino híbrido. Boston: Christensen Institute, 2018. Disponível em: https://www.blendedlearning.org/modelos/?lang=pt-br. Acesso em: 12 out. 2018. 
CHRISTENSEN, C. M. et al. Ensino híbrido: uma inovação disruptiva? Uma introdução à teoria dos híbridos. Boston: Christensen Institute, 2013.

COLL, C. et al. A Incorporação das Tecnologias de Informação e Comunicação na Educação: Do projeto técnico-pedagógico às práticas de uso. In: COLL, César; MONEREO, Carles (org.). Psicologia da Educação Virtual: Aprender e ensinar com as tecnologias da informação e comunicação. Porto Alegre: Artmed, 2010, p. 66- 96.

FONSECA, J. J. S. Metodologia da pesquisa científica. Fortaleza: UEC, 2002. Apostila.

HORN, M. B.; STAKER, H. Blended: usando a inovação disruptiva para aprimorar a educação. Prefácio Clayton M. Christensen. Porto Alegre: Penso, 2015.

MOREIRA, M. A. O que é afinal aprendizagem significativa? Quirriculum, San Cristóbal de La Laguna, n. 25, p. 29-56, mar. 2012. Disponível em: http://hdl.handle.net/10183/96956. Acesso em: 15 dez. 2018.

PIAGET, J. A. Equilibração das estruturas cognitivas: problema central do desenvolvimento. Rio de Janeiro: Zahar, 1976.

RIBEIRO, J.; MEDEIROS, L. C. de. Ensino híbrido: um desafio no aprender e ensinar. In: CONGRESSO PESQUISA DO ENSINO, 6., 2017, São Paulo. Anais [...]. São Paulo: Sinpro SP, 2017. Disponível em: http://www.sinprosp.org.br/conpe6/revendo/assets/-re---52-ens_hibrido_-desaf_-educ_-aprender_ensinar.pdf.pdf. Acesso em: 19 out. 2018.

TAFNER, M. A construção do conhecimento segundo Piaget. Cérebro \& Mente: Revista Eletrônica de divulgação científica em neurociência. Campinas, 1997. Disponível em: http://www.cerebromente.org.br/n08/mente/construtivismo/construtivismo.htm. Acesso em: 12 out. 2018.

Recebido em março de 2020.

Aprovado em maio de 2020. 